\title{
In Vitro and In Vivo Bioreactor Strategies for Bone Defect Repair
}

\author{
Massimo Rigoni ${ }^{*}$ and Devid Maniglio ${ }^{2}$ \\ ${ }^{1}$ Department of Provincial Health Services of Trento Orthopedics and Traumatology, Rovereto, Italy \\ ${ }^{2}$ Department of Industrial Engineering and Biotech Center for Biomedical Research, Trento, Italy
}

*Corresponding author: Massimo Rigoni, Department of Provincial Health Services of Trento Orthopedics and Traumatology, corso Verona 4, Rovereto, Italy

\begin{tabular}{|c|c|}
\hline ARTICLE INFO & ABSTRACT \\
\hline $\begin{array}{l}\text { Citation: Massimo Rigoni, Devid Maniglio. } \\
\text { n Vitro and In Vivo Bioreactor Strategies } \\
\text { or Bone Defect Repair. Biomed J Sci \& Tech } \\
\text { Res 24(4)-2020. BJSTR. MS.ID.004082. } \\
\text { Keywords: Bone Tissue Engineering; Bio- } \\
\text { eactors; Muscular Flap Prefabrication; } \\
\text { Periosteal Flap Prefabrication; Axial Vascu- } \\
\text { ar Bundle Prefabrication; Arteriovenous } \\
\text { coop Prefabrication; Critical Size Bone De- } \\
\text { ect }\end{array}$ & $\begin{array}{l}\text { The key elements for bioartificial bone formation in three-dimensional matrices in } \\
\text { any tissue engineering concept are a high number of osteogenic cells and supplies of } \\
\text { oxygen and nutrition [1]. In the treatment of large bone defect, tissue engineering is } \\
\text { challenging the problem to obtain scaffolds able to release growth and differentiation } \\
\text { factors for mesenchymal stem cells, osteoblasts and endothelial cells in order to achieve } \\
\text { faster mineralization and activate a stable vascularization. Bone is a highly vascular } \\
\text { structure: like all other living tissues, it is supplied by several blood vessels; on the } \\
\text { contrary cartilage is avascular, a lymphatic and has the lowest cellular density of any } \\
\text { tissue in the body with less than } 5 \% \text { cells by volume. Despite important progress in } \\
\text { engineered scaffolds for cartilage lesions, bone tissue scaffolds are still facing diffusion } \\
\text { issues, specially a lack of functional network of blood vessels. Three-dimensional } \\
\text { scaffolds used in bone tissue engineering, increase the complexity of the culture } \\
\text { because of the difficulty in supplying oxygen and nutrients to the cells. Researchers are } \\
\text { developing in vitro and in vivo bioreactor based strategies for solving these functional } \\
\text { problems. The concept of bioreactor for growing "functional engineered tissues" has not } \\
\text { only an in vitro application but can be extended to an in vivo approach. The aim of this } \\
\text { mini review is to analyze current trends in applying the concept of bioreactor to bone } \\
\text { tissue engineering, comparing in vivo and in vitro methods currently proposed for future } \\
\text { critical size skeletal defect repair in reconstructive surgery. }\end{array}$ \\
\hline
\end{tabular}

\section{Introduction}

The ideal bone graft has several features that can be achieve in different ways combining in vitro and in vivo approaches. Bone is a dynamic, highly vascularized tissue with the unique capacity to heal and remodel without leaving a scar [2]. An ideal functional bone graft should have some important characteristics like biological safety, osteoinductive and angiogenic potentials, low donor site morbidity, no size restrictions, rapid accessibility to surgeons, long shelf life and reasonable cost. Even if for bone defect reconstruction several strategies have been already applied, none of currently available bone substitutes own all the above-mentioned properties. The present mini review focuses on the different solutions adopted to create bone scaffolds using bioreactors starting from the clinician "in vivo" and scientist "in vitro" point of view. Bioreactors is an apparatus for growing an organism or cells in the context of cell culture. The term bioreactor it may refer to any manufactured or engineered device or system capable to support a biologically active environment. Bioreactors are classically used in industrial fermentation processing, wastewater treatment, food processing and production of pharmaceuticals and recombinant proteins (e.g. antibodies, growth factors, vaccines, and antibiotics).

Bioreactors in the field of bone tissue engineering they are important because are able to provide an in vitro environment mimicking the in vivo conditions; for example mechanical compression and hydrostatic fluid pressure are important regulating factors for cell physiology in bone and can facilitate tissue formation $[3,4]$. Several studies have demonstrated promising results when in vitro dynamic conditions were applied before implantation, describing the effect of many variable and how those can influence 
cell metabolisms [5-7]. Furthermore, bioreactors provide more standard culture conditions than in vivo tissue regeneration, thus it is useful for systematic, controlled studies of cellular differentiation and tissue development in response to biochemical and mechanical cues. Regenerative medicine takes advantage of the body natural capacity to regenerate, on the contrary in tissue engineering bone substitute are manufactured in an industrial setting despite the need for adaptation in the human body. The borders between regenerative medicine and tissue engineering are today narrower, often merging in a bigger topic (TERM), determining the foundation and growth of an international scientific society has been founded with the mission of bring together the international community engaged or interested in both fields (TERMIS). All engineered tissues need adaptation in human body and artificial bone tissue had been experienced vascularity issues and creeping substitution when implanted in clinical setting. That's the main reason why in vivo bioreactor concept has been proposed: microsurgery techniques and tissue engineering are ideally mixed in order to increase the quality of artificial bone substitute.

\section{In Vitro Bioreactors}

Tissue engineering aims to realize biological functional substitutes to be used to repair or regenerate damaged tissues. Tridimensional scaffolds are necessary to sustain living and functional constructs. They are designed to be biodegradable and bioresorbable, made of synthetic or natural origin materials, to have specific chemical properties and to exhibit the proper geometrical dimensions, structure and chemistry as close as possible to the original tissue. To achieve tissue remodeling, cell culture must tangibly differ from the traditional static 2D culture. In fact, traditional cell cultures are usually carried out on multi-well polystyrene plate, containing a specific treated surface to promote cell adhesion. Cells are seeded with medium and then plates are placed in an humified incubator where the environmental conditions of $37^{\circ} \mathrm{C}$ and $5 \% \mathrm{CO}_{2}$ are maintained. The temperature is, obviously, physiological, while the $\mathrm{CO}_{2}$ is necessary to stabilize $\mathrm{pH}$ in the culture. As previously mentioned, a bioreactor can be defined as any apparatus that attempts to mimic physiological conditions in order to maintain and encourage tissue regeneration, simulating the living organism. In a bioreactor, tissue culture is a non-steady state process in which all parameters can be measured and controlled. Precisely, temperature, $\mathrm{pH}$ of the medium, gas exchange, $\mathrm{O}_{2}$ and $\mathrm{CO}_{2}$ level, humidity, nutrient flow and waste removal. Moreover, mechanical-biochemical stimuli can also be tuned.

Temperature must be constant around $37^{\circ} \mathrm{C}, \mathrm{pH}$ value should remain between 7.2 and 7.4 acting on $\mathrm{CO}_{2}$ level. Humidity should be enough (generally closed to condensation) to avoid medium evaporation, while dissolved $\mathrm{O}_{2}$ level and nutrient concentrations must be enough to guarantee cell functions. The fundamental part of a bioreactor is the culture chamber: a sterile environment where the cellular constructs are housed. The seeded scaffold can be confined, that means laterally constrained, or unconfined, in which the lateral side is free to move. Growing medium with the necessary nutrients can flow inside the chamber thanks to a predisposed system. The culture medium can diffuse inside the substrate with a proper flow regime, allowing nutrients transport and waste removal. The culture chamber must also present some general characteristics: each component must be sterilized and manufactured from nontoxic materials and should be easy to assemble, still allowing parameter measurements along the medium flow line. It is difficult to carry out a continuous on-line measure, especially considering biochemical signals. So, a bioreactor may be designed, considering the possibility to introduce custom on-line sensors or, alternatively, an apparatus for sampling small quantity of medium for batch external analysis.

A bioreactor is thus developed to cultivate cells under proper dynamic conditions, close to the physiological in vivo environment, applying biochemical and mechanical stimuli to improve the tissueengineered constructs properties. In fact, mechanical stresses can produce changes in cell shape and behavior, inducing a wide biochemical response which includes the secretion of bioactive molecules such as growth factors, vasodilators, ECM proteins, adhesion proteins, and others. In the same way, the local inoculation of biochemical signals on cells can lead to specific genes activation. Considering these factors is crucial to obtain an engineered construct with adequate properties. Therefore, it is essential to evaluate the normal living tissue conditions to develop a suitable device for driving cell functions and biosynthesis. In fact, an ideal bioreactor design, which covers different tissue engineering applications, does not exist, but can be tailored for a specific individual aim. A bioreactor for tissue engineering applications should, at some level

\section{(i) Facilitate uniform cell distribution;}

(ii) Provide and maintain the physiological requirements of the cell (e.g., nutrients, oxygen, growth factors);

(iii) Increase mass transport both by diffusion and convection using mixing systems of culture medium;

(iv) Expose cells to physical stimuli; and

(v) Enable reproducibility, control, monitoring and automation [8].

While the most sophisticated bioreactors allow the integration of all these functions, while usually are quite complex to setup, the simplest ones, are sometimes preferred because are easier to handle, but are limited in functions. Among all bioreactors, spinner flasks (Figure 1a) are the most dated and their introduction is derived from the previous experience in agriculture and food applications, as fermenters. In these reactors, usually constituted of glass transparent flasks, a turbulent flow is imposed to increase nutrient and oxygen diffusion. The cell-seeded scaffolds are typically immersed in the medium and suspended using needles. Continuous 
stirring of the culture medium ensures abundant diffusion. The non-homogeneity of the medium flow inside the spinner flask is the main defect of this bioreactor, which makes it difficult to analyze and model the metabolites exchange and quantify the hydrodynamic stimulation, resulting in an inadequate mass transfer which can lead to cause cell damage or apoptosis. This usually results in constructs characterized by a high cell density in the outer part, because of a poor nutrient diffusion inside the scaffolds. A similar approach is exploited in the Rotating Wall Vessel (RVW). RWV is composed by a cylindrical chamber where the scaffold is cultured surrounded by medium and left in suspension while subjected to a continuous rotation, which produces an effect of microgravity. Gas exchange is guaranteed by the presence of a silicone membrane or a bacterial filter. Some variations of this system are available, such as slow turning lateral vessel (STLV) and high aspect ratio vessel (HARV). In these special configurations, by changing the flow from non-homogeneous to a constant profile, it is possible to vary the nutrient gradient in the chamber (Figure 1b) [9].
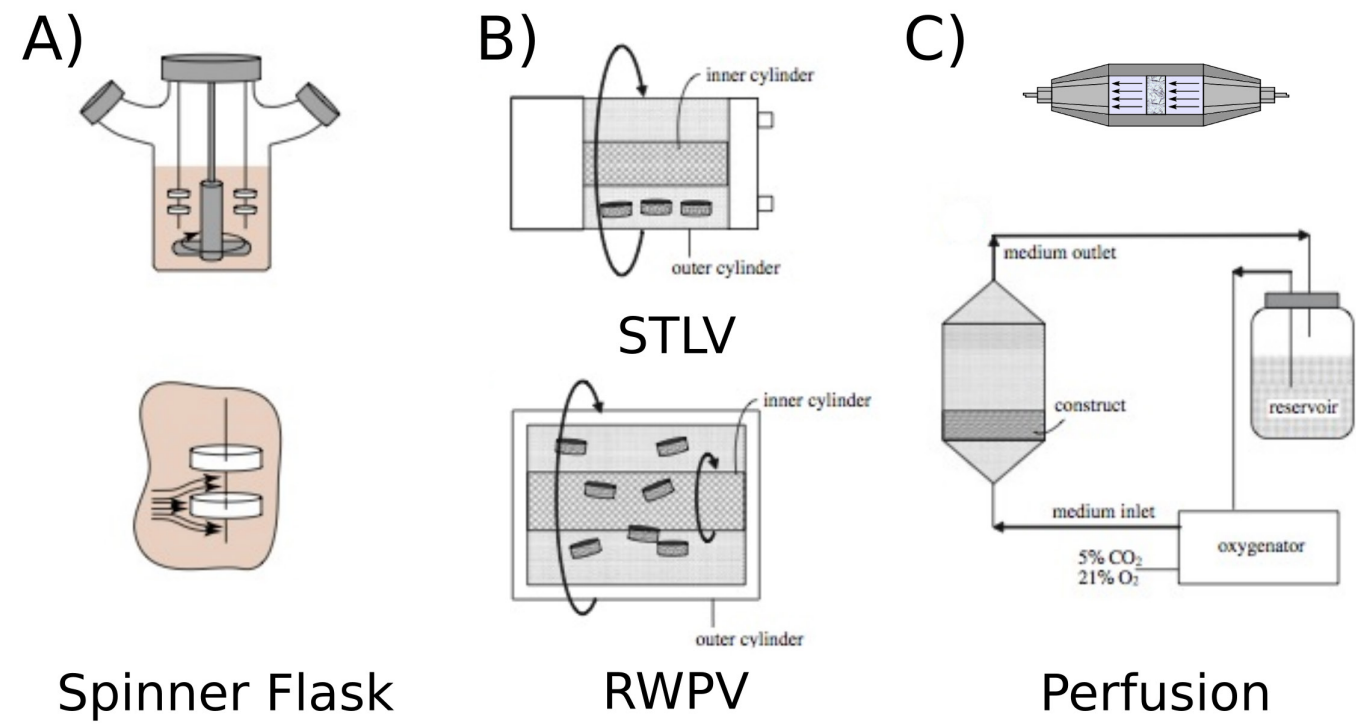

\section{Perfusion}

Figure 1: Bioreactor layout:
A) Spinner flask,
B) STLV and RWPV,
C) C) Perfusion.

Bioreactors are mainly designed to guarantee a correct oxygen saturation and a proper medium exchange, improving the cell construct characteristics and accelerating the in vitro maturation. However, to mimic the in vivo conditions where bone cells are subjected to mechanical loads, several and more complex bioreactor configurations capable of providing direct or indirect mechanical stimulation have been proposed. While the stimulation can be obtained by tuning the fluid flow, acting on the perfusion dynamic or applying a pulsatile flow, as an alternative or in combination, stretching, direct compression and hydrostatic pressure have been reported to produce good results and benefit to cells $[10,11]$. The introduction of perfusion allows nutrients transport and waste removal directly through the scaffold bulk, to overcome the limitations of diffusion. In perfusion bioreactors, porous scaffolds are usually housed on an impermeable chamber so that the culture medium can be forced to pass through (Figure1c). The perfusion influences osteocytes/chondrocytes characteristics, such as matrix synthesis gene expression and generally stimulates cell proliferation and matrix synthesis compared to the traditional static cultures [9,12-14]. While perfusion allows improving gas and medium exchange, it is also capable to activate gene expression, upregulating alkaline phosphatase (ALP) and calcium deposition $[15,16]$. Similar results were reported in the case of bioreactors capable to apply direct hydrostatic pressure. In general, a hydrostatic compression bioreactor can apply either intermittent (ICP) or cyclical (CCP) pressure, imposing to the liquid or the gas a square wave pulse, or a sinusoidal pressure profile $[17,18]$.

Particular attention should be spent for direct compression bioreactors. In fact, in these devices mechanical stimuli are proved to stimulate cell activation by mechano-transduction, even if a prolonged application can lead in some cases to cell damage or apoptosis. In contrast to static culture, mass transfer is considerably improved in compression bioreactor culture since compression leads to the fluid flow through the scaffold [19]. Short-term mechanical stimulation enhanced the expression of several genes encoding for factors involved in osteogenesis, such as annexin- $\mathrm{V}$, osteopontin, integrin- $\beta 1$, PDGF $\alpha$, RUNX2, TGF $\beta R 1$, and SMAD5. 
These experiments demonstrate that even short mechanical stimuli can be enough to activate the osteogenic differentiation pathways in human mesenchymal stem cells [8]. Moreover, osteogenic saturation due to continuous loading was recently resolved by introducing short ( $5 \mathrm{~s}, 10 \mathrm{~s}$ and $15 \mathrm{~s}$ ) rest periods to the stimulus application, permitting the increasing of intracellular calcium ions and osteoporin contents [20-23]. The research on bioreactors and the increase in complexity was the stimulus for the technology transfer from the research laboratories to spin-off companies like Bose, Cellec or Bio Tools, that have proposed bioreactors for bone and cartilage as products. These bioreactors are usually characterized by partial or full automated control over the culture parameters, allowing to work in diffusion or perfusion mode and permitting the application of external mechanical stimuli under direct compression or tensile strength conditions.

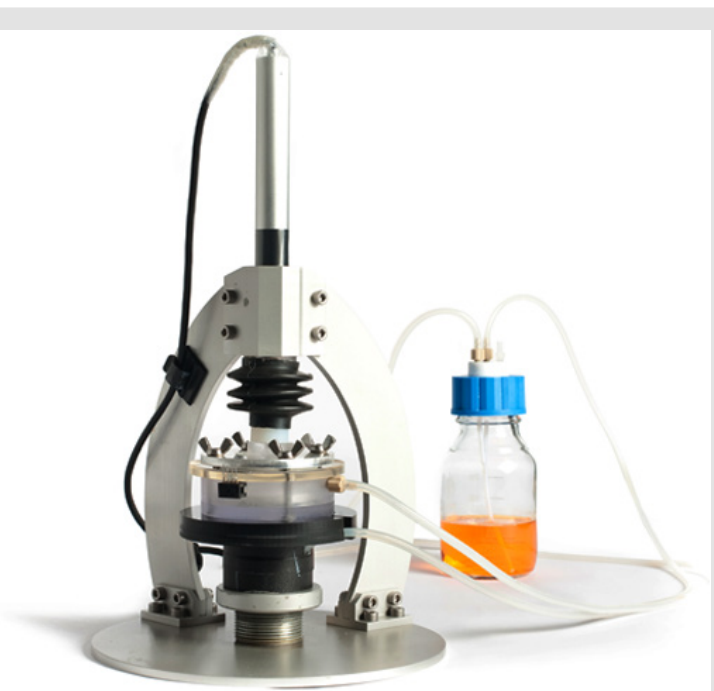

Figure 2: Bioreactor design proposed by Bio Tools.

The bioreactor proposed by Bio Tools (a start-up company of the University of Trento constituted in 2010, Figure 2) could represent an example of refinement and complexity. The device proposed is mainly constituted by a sealed cell culture chamber that allows the incorporation of several scaffolds and can be set to work in diffusion or perfusion flow. The upper part of the chamber hosts a silicon rubber membrane that allows the application of the external stimulation provided by a linear motor installed on the top of the reactor. While the stimulation is applied the effective load is measured by means of a load cell placed at the bottom of the culture chamber. In this way it is possible to program a stimulation and calibrate the effective stress/strain applied to the scaffolds. By modifying the geometry, the system also permits the application (and measurement) of a hydrostatic pressure. The bioreactor can be programmed to apply different stimulation cycles, with user programmable shape (sinusoidal, triangular, sawtooth, trapezoid shape), intensity, duration and number. Contemporary, during the standard operation, the bioreactor is designed to monitor also temperature and $\mathrm{CO}_{2}$ levels, and to control the medium exchange.
Bioreactors from other brands follow similar approaches, with slightly different design. Despite the high technical complexity of the current bioreactor design, still the problem of proper scaffolds feeding with nutrients is not completely resolved and, while they allow better proliferation of cells in the scaffolds, they start manifesting some limitations when their size is bigger than few millimeters.

\section{In Vivo Bioreactors}

The concept of "in vivo" bioreactors is inherent in the body selfregenerative capacity. However, mixing bone tissue engineering with body's self-regenerative capacity to regenerate new tissue is a relatively new approach in critical size skeletal defects and, despite numerous different techniques and studies in small and large animal models, only a few clinical applications with successful results are reported in medical literature. The core of this novel approach is microsurgery with flap prefabrication and other techniques to vascularized artificial bone scaffolds. In vivo bioreactors approach is an emerging strategy for bridging the in vitro gap between experimental successes and clinical translation in managing scaffolds manipulation, seed cells seeding and growth factors delivery for bone defect reconstruction. This principle focuses on using the body itself as a bioreactor, hosting the traditional triad (scaffold, seed cells, and growth factors). Prefabrication of vascularized bioartificial bone grafts in vivo might be an alternative to in vitro tissue engineering techniques. Combining tissue engineering approaches with flap prefabrication techniques may allow the application of vascularized bioartificial bone grafts grown in vivo with the advantage of minimal donor site morbidity, if compared with conventional vascularized bone grafts. Prefabrication is a surgical term first introduced by Yao in 1982 [24] and that describes the implantation of a vascular pedicle into a new territory, followed by a neovascularization period and subsequent tissue transfer based on its implanted pedicle.

Tissue prefabrication is commonly realized in two steps. Initially, the selected tissue, is designed into the required configuration and is then implanted in the convenient body area for the introduction of a vascular pedicle. Subsequently, during the second step, the autologous implant is harvested with the surrounding tissue and the vascular pedicle as a free flap. While the flap is connected to the local circulation by means of a microvascular anastomosis, the implant acquires its vascularization from the tissue block. Flap are prefabricated basically using two strategies: wrapping the bone graft in axially vascularized tissues (cutaneous, fasciocutaneous or muscle flaps) or implanting a vascular axis into the bone graft itself (intrinsic mode vascularization). With the intrinsic mode, the construct acquires naturally a native perfusion, without relying on favorable local environmental conditions. This can be fundamental in case of trauma or tumor [25]. The recent induction of intrinsic vascularization techniques for scaffolds maturation allowed obtaining, for several animal models, vascularized tissues directly 
transferable as pedicles or free flaps. Four different techniques are, at present, the most interesting approaches proposed in microsurgery for vascularizing an artificial tissue: muscular flap prefabrication, periosteal flap prefabrication, axial vascular bundle prefabrication, arteriovenous loop prefabrication.

\section{Muscular Flap or Pouch}

A perfused muscle is a poor bed for cancellous bone graft but local condition of good perfusion which are likely to be obtained with fascial or muscular flap wrapped around an autologous bone graft could promote bone tissue regeneration (Figure 3) [26]. Vascularization induced by this method is called "inosculation", in which blood vessel already present in the graft rapidly connect with the vascularized muscular flap. The preformed micro-vessels simply must develop interconnections to the host microvasculature to get fully blood perfused within a short period of time. Although inosculation of preformed micro-vessels is a very promising strategy in tissue engineering, some studies have shown that adequate blood perfusion of artificial bone graft is not guaranteed during the very first days after implantation of the tissue construct $[27,28]$ and much of the inosculation process has to rely on favorable local conditions. Bone formation beneath "standard muscular flaps" has been successfully induced using bioceramics scaffolds seeded with autologous bone marrow stromal cells $[29,30]$. Prefabricated vascularized bone grafts have also been tested for jaw reconstruction with a thorough in vivo evaluation in a pig model [31,32].
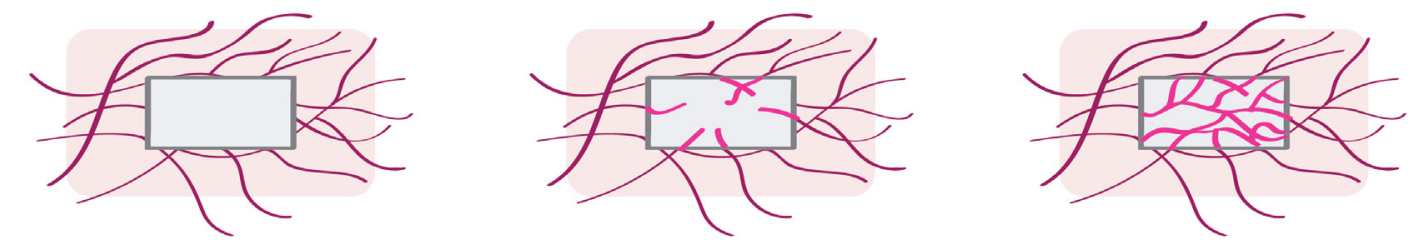

Figure 3: Inosculation process induced by muscular flap or pouch technique.

In the clinical setting, a large mandibular defect was successfully reconstructed using custom made titanium cage, realized according to CT scan followed by 3D reconstruction and filled with bone marrow aspirate, xenogeneic bone minerals and OP-1, after a prefabrication period of 7 weeks. The patient obtained both a functional and an esthetic mandibular reconstruction. This landmark case has offered a novel method for realizing custom bone grafts, meanwhile avoiding the development of secondary bone defects. Taking inspiration from these promising results, researchers continue to apply, trying to improve the muscle strategy for applications in clinical cases [33]. There is the need of new "in vitro" techniques to improve the inosculation process "in vivo", some recent studies have demonstrated the effectiveness of combining these two approaches to improve bone graft vascularity [34]. The use of a muscular pouch for improving blood vessel network formation in artificial bone grafts is, by now, the most used strategy within the concept of "in vivo bioreactors" and is reported in several studies both on small and large animal models. As for now, it is the only in vivo strategy that has been applied in a clinical setting and whose potentialities were demonstrated on humans.

\section{Periosteal Flap}

In the periosteal flap strategy, a periosteal flap is used to wrap the tissue-engineered construct or to cover the chamber containing the tissue-engineered construct. Therefore, the periosteumconstruct combination forms an in vivo bioreactor capable of providing pluripotent cells and molecular signals, actively stimulating the bone formation process. This results in a woundhealing response within the space, leading to new bone formation, instead of fibrotic scar. The periosteum is a promising cell source for bone regeneration strategies in function of its role in recruiting skeletal progenitor cells. The potential of inner periosteum layer to generate new bone has been clinically recognize through the vast and enduring clinical experience with Judet decortication procedure. The osteoperiosteal decortication procedure described by Judet [35] consist in the dissection of the bone periosteum membrane from the cortex, using a sharp chisel, so that small bone pieces remain attached to periosteal tissue; bone chips 1 to $3 \mathrm{~mm}$ thick are elevated for $5-10 \mathrm{~cm}$ proximal and distal to the fracture site and for $60-75 \%$ bone circumference. Osteoperiosteal decortication is a reliable technique that leads to predictable, satisfactory results. Although this technique has been in use for a long time, it continues to be effective for treating diaphyseal nonunion [36].

The Masquelet technique for bone gap is based on the application of a cement spacer within a fixed bone defect, whose role is to provide mechanical stability and to act as a foreign body that allows the propagation of periosteal-like membrane on its surface [37]. In orthopedic surgery the use of periosteal flap is widespread. The medial femoral condyle as a free cortico periosteal flap has demonstrated its potential when applied to upper limb defects [38]. Some studies have demonstrated a better new tissue formation when comparing with bone graft implanted against muscle fascia $[39,40]$. The use of periosteal flap to wrap tissue engineered construct in the rat femur was reported by Vögelin E. to significantly increased bone formation and prevented heterotopic ossification $[41,42]$. A variety of animal models have demonstrated the validity of periosteal flap approach in bone regeneration [43- 
45]. Vacanti CA et al. reported a case of a man who had a traumatic avulsion of the dorsal skin and distal phalanx of the thumb. They used periosteum's cells expanded in vitro in combination with a porous hydroxyapatite scaffold to replace the distal phalanx of the thumb. Although a decent functional result, a biopsy of the implant 10 months after surgery showed that only $5 \%$ of the implant resulted being constituted by new bone [46]. The main limitation of periosteal flap strategy is the lack of a large enough periosteal flap donation site for the treatment of critical size bone defect. Integration between in vitro cell expansion technique to periosteal flap strategy will be critical in the future of this way of bone reconstruction.

\section{Axial Vascular Bundle (AVB)}

The Axial Vascular Bundle strategy (Figure 4), unlike the random blood vessel pattern in the subcutaneous pockets and tissue flaps, is an inherent model of axial osteogenesis and vascularization for prefabrication of bone grafts. In this methodology, an artery and a vein are inserted centrally inside a scaffold and are supposed to transport progenitor/stem cells, cytokines, oxygen, and nutrients and to remove waste products. Therefore, an extensive vascularization and osteogenesis of the scaffold should be obtained. The main limitation of the AVB model is that it can provide only a small contact surface within the scaffold and, for this reason, it is difficult to provide a short pre-fabrication period. As an alternative approach, a hybrid solution, like the envelopment of the scaffold with a muscular flap or a periosteal flap, is possible. The combined use of the AVB and tissue flap to form an IVB is advantageous, due to the utilization of two well-established bone graft prefabrication strategies, which makes it the most frequently applied model in small and large animal studies. Kokemueller et al. in 2010 have applied this model for a mandibular bone reconstruction in vivo for the first time [1].

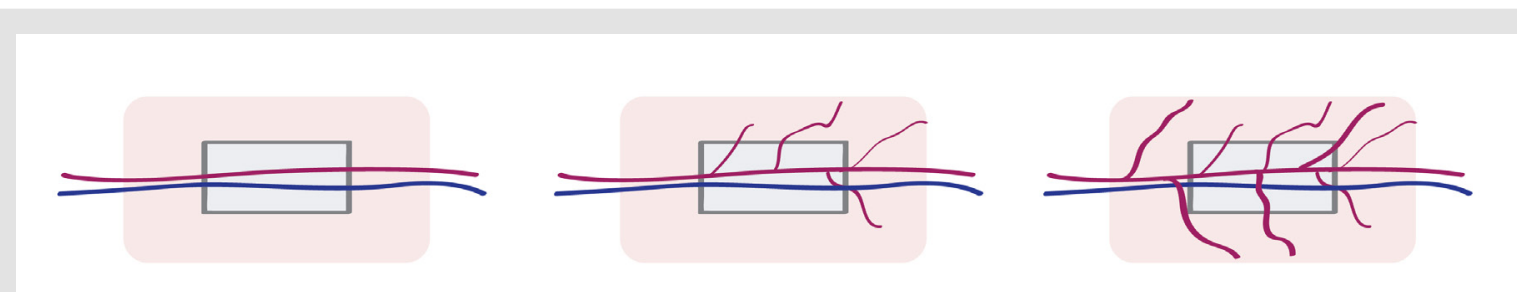

Figure 4: Intrinsic vascularization induced by axial vascular bundle technique.

\section{Arteriovenous loop (AV loop)}

Erol and Spira in 1980 developed in a rat an arterio-venous loop model interposing a venous graft between the femoral artery and vein in the thigh, to create a prefabricated full thickness skin graft. with this they also described the first AV-loop model [47]. The creation of a vascular axis using vein grafts holds promise for generation of vascularized bone units relatively independent of anatomical limitations and without the creation of a significant donor site defect [47-50]. Inadequate adjacent arterial supply and venous outflow either due to the injury or to preexisting vascular disease may preclude the use of an axial vascular bundle as an in vivo bioreactor in the skeletal defect site. In these cases, arteriovenous loop can be a good solution for bone graft prefabrication. Normally, an arteriovenous loop is realized by a direct microsurgical anastomosis of an artery and a vein or by the interposition of a venous graft between an artery and a vein, to form an arteriovenous fistula (Figure 5). The arteriovenous loop is then implanted inside a cavity containing a scaffold, realizing in this way an in vivo bioreactor. A perfused capillary network will sprout from a central vessel into the surroundings, remodeling to produce arterioles, postcapillary venules, and venules. This will finally result in an accelerated vascularization and, consequently, in and new functional tissue maturation.
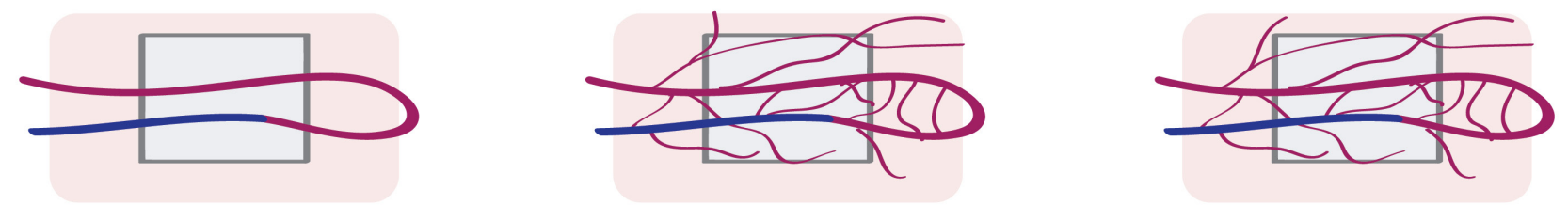

Figure 5: Arteriovenous loop method.

Arteriovenous loop strategy has demonstrated an evident superiority over the axial vascular bundle in terms of both axial angiogenesis and osteogenesis [51]. In principle, three mechanisms are considered responsible for the accelerated angiogenesis: the local inflammation due to the surgical trauma on the vessels which promotes the release of inflammatory factors and the development of the capillary network, the elevated vascular flow shear stress on the venous wall due to arterialization, which promotes the growth of collateral vessels and increases the number of micro-vessels, and the gradient hypoxia within the matrix, which determines 
the upregulation of the hypoxia-inducible factor 1 , together with the expression of several angiogenic factors. In addition, the arteriovenous loop method can be realized in any surgical site, then transferred as a free flap by means of microsurgery techniques, without considering the vascular pedicle length. This fact greatly expands the clinical potential application of this technique. There are plenty of studies in small and large animal models in which the A-V loop strategy has been applied. Ideally A-V loop is the most advantageous microsurgical technique to vascularize a bone scaffold and has the great convenience to be a one-step procedure. Horch R.E. et al. have successfully applied axially vascularized in situ tissue engineered for large bone defect in two clinical cases of bone gap after osteomyelitis using the A-V loop model [52]. The main limitation of this model are the difficulties to shape a load bearing bone around the A-V loop.

\section{Conclusion}

The ideal bone graft is not yet in the reconstructive surgeon's armamentarium. Although applying the concept of "in vivo" bioreactor we could experience soon encouraging clinical application: functional bone reconstruction, in fact, requires the regenerated bone grafts to possess mechanical strength, microstructure, and functions as close as possible to native bone tissue. However, ectopically regenerated bone grafts remain far to be considered equivalent to the native bone tissue, in their histological structure. As an example, only $17 \%$ of the bone graft prefabricated in Heliotis' clinical case resulted to be bone tissue, while the remaining tissue was 37\% HA and $46 \%$ fibrovascular tissue. In Vacanti et al. thumb reconstruction a biopsy of the implant 10 months after surgery showed that only $5 \%$ of the implant was new bone. On the other hand, "in vitro" bioreactors designed for bone tissue engineering, in some of their interpretation seem to suffer of excessive simplification, reducing to standard perfusion enhancement of 3D constructs, without introducing controllable mechanical stimulation and allowing adequate constructs evolution monitoring. In some others, because of their complexity, for their optimal setup they require specialized operators, limiting their wide diffusion. In all the cases they still have not been yet capable to resolve the problem of vascularization. Until now, only muscular pouch prefabrication has emerged as the only "in vivo" bioreactors strategy that has been applied with success in clinical setting. It was of significance to have found new "in vitro" techniques adapted to the muscular pouch prefabrication process for increasing the artificial bone graft vascularization. Microsurgery through the concept of "in vivo bioreactors" needs in vitro techniques to find a solution for critical size skeletal defects. The union between clinician and scientist point of view is fundamental in the difficult process of transforming engineered bone tissue into limitless vascularized bone graft.

A comparison of the in vitro and in vivo strategy can be done considering the advantages deriving from the two approaches: a) The in vitro approach allows the realization of ad-hoc scaffolds to cover bone gaps with precision after 3D imaging reconstruction (CT or MRI); it utilizes just artificial resources without any donor site morbidity; it uses standardized tissue manufactured in controlled close system, with consequent reduction of costs.

b) The in vivo approach permits to implant a tissue ready to his function; provides a tissue with a vascular network through microsurgery techniques; allows to implant a bone graft that doesn't undergo creeping substitution; permits the reconstructing of tissue loss in one procedure.

In the present literature, it was hard to find a single winning approach to bone reconstruction: in most cases different strategies were applied together to create engineered bone tissue, as evidenced both in small and large animal studies. Even if the body osteogenicity capacity, emblematic in pathologic heterotopic bone formation, it is well known; the new bone formation needs artificial scaffolds and growth factors in the case of critical size defects. Considering that neither scientists neither the microsurgeons could solve alone the problem of critical size bone reconstruction in trauma, the most promising approach is probably integration of the different approaches. The route to a vascularized bone graft could, as a principle, starts from the "in lab" realization of a cell constructs with osteocyte phenotype expressed and bone synthesis genes activated taking full advantage of the in vitro bioreactor approach. Only at this time, the alive, but non-vascularized cell construct could undergo to "in vivo" bioreactor maturation for vascularization development. Such a multidisciplinary approach would inevitably imply the integration of knowledge and side-by-side collaboration of clinicians, engineers, biologists and physicists, the only key for a successful ending.

\section{References}

1. Kokemueller H, Spalthoff S, Nolff M, Tavassol F, Essig H, et al. (2010) Prefabrication of vascularized bioartificial bone grafts in vivo for segmental mandibular reconstruction: experimental pilot study in sheep and first clinical application. Int J Oral Maxillofac Surg 39(4): 379-387.

2. Buckwalter J, Einhorn T, Marsh JL (2001) Bone and Joint Healing. Rockwood Green's Fract adults 245-271.

3. Martin I, Wendt D, Heberer M (2004) The role of bioreactors in tissue engineering. Trends Biotechnol 22(2): 80-86.

4. Butler DL, Goldstein SA, Guilak F (2000) Functional tissue engineering: The role of biomechanics. J Biomech Eng 122(6): 570-575.

5. De Croos JNA, Dhaliwal SS, Grynpas MD, Pilliar RM, Kandel RA (2006) Cyclic compressive mechanical stimulation induces sequential catabolic and anabolic gene changes in chondrocytes resulting in increased extracellular matrix accumulation. Matrix Biol 25(6): 323-331.

6. Huang CYC, Hagar KL, Frost LE, Sun Y, Cheung HS (2004) Effects of Cyclic Compressive Loading on Chondrogenesis of Rabbit Bone-Marrow Derived Mesenchymal Stem Cells. Stem Cells 22(3): 313-323.

7. Altman GH, Lu HH, Horan RL, Tara C, Daniel R, et al. (2002) Advanced bioreactor with controlled application of multi-dimensional strain for tissue engineering. J Biomech Eng 124(6): 742-749. 
8. Sladkova M, de Peppo G (2014) Bioreactor Systems for Human Bone Tissue Engineering. Processes 2(2): 494-525

9. Chen HC, Hu YC (2006) Bioreactors for tissue engineering. Biotechnol Lett 28(18): 1415-1423.

10. Chaudhuri J, Al Rubeai M (2005) Bioreactors for Tissue Engineering: Principles, Design and Operation. Springer.

11. Basso N, Heersche JNM (2002) Characteristics of in vitro osteoblastic cell loading models. Bone 30(2): 347-351.

12. Bancroft GN, Sikavitsas VI, Mikos AG (2003) Technical Note: Design of a Flow Perfusion Bioreactor System for Bone Tissue-Engineering Applications. Tissue Eng 9(3): 549-554.

13. Pazzano D, Mercier KA, Moran JM, Stephen SF, David DD, et al. (2000) Comparison of Chondrogensis in Static and Perfused Bioreactor Culture. Biotechnol Prog 16(5): 893-896.

14. Watanabe S, Inagaki S, Kinouchi I, Takai H, Masuda Y, et al. (2005) Hydrostatic pressure/perfusion culture system designed and validated for engineering tissue. J Biosci Bioeng 100(1): 105-111.

15. Glowacki J, Mizuno S, Greenberger JS (1998) Perfusion enhances functions of bone marrow stromal cells in three- dimensional culture. Cell Transplant 7(3): 319-326

16. Sailon AM, Allori AC, Davidson EH, Reformat DD, Allen RJ, et al. (2009) A Novel Flow-Perfusion Bioreactor Supports 3D Dynamic Cell Culture. J Biomed Biotechnol 2009: 1-7.

17. Nagatomi J, Arulanandam BP, Metzger DW, Meunier A, Bizios R (2001) Frequency- and Duration-Dependent Effects of Cyclic Pressure on Select Bone Cell Functions. Tissue Eng 7(6): 717-728.

18. Roelofsen J, Klein-Nulend J, Burger EH (1995) Mechanical stimulation by intermittent hydrostatic compression promotes bone-specific gene expression in vitro. J Biomech 28(12): 1493-1503.

19. Fritton SP, Weinbaum S (2009) Fluid and Solute Transport in Bone: FlowInduced Mechanotransduction. Annu Rev Fluid Mech 41(1): 347-374.

20. Batra NN, Li YJ, Yellowley CE, You L, Amanda MM, et al. (2005) Effects of short-term recovery periods on fluid-induced signaling in osteoblastic cells. J Biomech 38(9): 1909-1917.

21. Yamamoto K, Tomita N, Fukuda Y, Suzuki S, Igarashi N, et al. (2007) Time-dependent changes in adhesive force between chondrocytes and silk fibroin substrate. Biomaterials 28(10): 1838-1846.

22. Waldman SD, Couto DC, Grynpas MD, Pilliar RM, Kandel RA (2006) A single application of cyclic loading can accelerate matrix deposition and enhance the properties of tissue-engineered cartilage. Osteoarthr Cartil 14(4): 323-330.

23. Robling AG, Burr DB, Turner CH (2000) Partitioning a Daily Mechanica Stimulus into Discrete Loading Bouts Improves the Osteogenic Response to Loading. J Bone Miner Res 15(8): 1596-1602.

24. Yao ST (1982) Microvascular Transplantation of Prefabricated Free Thigh Flap. Plast Reconstr Surg 69(3): 568.

25. Kneser U, Schaefer DJ, Polykandriotis E, Horch RE (2006) Tissue engineering of bone: the reconstructive surgeon's point of view. J Cell Mol Med 10(1): 7-19.

26. Cherubino M, Ronga M, Sallam D, Fagetti A, Valdatta L, et al. (2016) Treatment of Radial Nonunion with Corticocancellous Bone Graft and Fascia of Anterolateral Thigh Free Flap. Plast Reconstr Surg - Glob Open 4(12): e1149.

27. Terheyden H, Warnke P, Dunsche A, Soren J, Brenner W, et al. (2001) Mandibular reconstruction with prefabricated vascularized bone grafts using recombinant human osteogenic protein 1: an experimental study in miniature pigs. Part II: Transplantation. Int J Oral Maxillofac Surg 30(6): 469-478.

28. Laschke M, Vollmar, Menger M (2011) The dorsal skinfold chamber: window into the dynamic interaction of biomaterials with their surrounding host tissue. Eur Cells Mater 22: 147-167.
29. Casabona F, Martin I, Muraglia A, Berrino P, Santi P, et al. (1998) Prefabricated Engineered Bone Flaps: An Experimental Model of Tissue Reconstruction in Plastic Surgery. Plast Reconstr Surg 101(3): 577-581.

30. Bernard SL, Picha GJ (1991) The Use of Coralline Hydroxyapatite in a “Biocomposite" Free Flap. Plast Reconstr Surg 87(1): 96-105.

31. Tremblay PL, Hudon V, Berthod F, Germain L, Auger FA (2005) Inosculation of Tissue-Engineered Capillaries with the Host's Vasculature in a Reconstructed Skin Transplanted on Mice. Am J Transplant 5(5): 1002-1010.

32. Terheyden H, Menzel C, Wang H, Springer I, Rueger D, et al. (2004) Prefabrication of vascularized bone grafts using recombinant human osteogenic protein 1-part 3: dosage of rhOP-1, the use of external and internal scaffolds. Int J Oral Maxillofac Surg 33(2): 164-172.

33. Warnke P, Springer I, Wiltfang J, Acil Y, H Eufinger, et al. (2004) Growth and transplantation of a custom vascularised bone graft in a man. Lancet 364(9436): 766-770.

34. Laschke M, Mussawy H, Schuler S, Eglin D, Alini M, et al. (2010) Promoting external inosculation of prevascularised tissue constructs by pre-cultivation in an angiogenic extracellular matrix. Eur Cells Mater 20: 356-366.

35. Judet R, Judet J, Orlandini J, Patel A (1967) La décortication ostéomusculaire. Rev Chir Orthop 53: 43-63.

36. Guyver P, Wakeling C, Naik K, Norton M (2012) Judet osteoperiosteal decortication for treatment of non-union: The Cornwall experience. Injury 43(7): 1187-1192.

37. Pelissier P, Martin D, Baudet J, Lepreux S, Masquelet AC (2002) Behaviour of cancellous bone graft placed in induced membranes. Br J Plast Surg 55(7): 596-598.

38. Fuchs B, Steinmann SP, Bishop AT (2005) Free vascularized corticoperiosteal bone graft for the treatment of persistent nonunion of the clavicle. J Shoulder Elb Surg 14(3): 264-268.

39. Hertel R, Gerber A, Schlegel U, Cordey J, Rüegsegger P, et al. (1994) Cancellous bone graft for skeletal reconstruction Muscular versus periosteal bed - Preliminary report. Injury 25(s1): SA59-SA70.

40. Brey EM, Cheng MH, Allori A, Satterfield W, Chang DW, et al. (2007) Comparison of Guided Bone Formation from Periosteum and Muscle Fascia. Plast Reconstr Surg 119(4): 1216-1222.

41. Vögelin E (2005) Healing of a Critical-Sized Defect in the Rat Femur with Use of a Vascularized Periosteal Flap, a Biodegradable Matrix, and Bone Morphogenetic Protein. J Bone Jt Surg 87(6): 1323-1331.

42. Hutmacher DW, Sittinger M (2003) Periosteal Cells in Bone Tissue Engineering. Tissue Eng 9(supplement 1): 45-64.

43. Breitbart AS, Grande DA, Kessler R, Ryaby JT, Fitzsimmons RJ, et al. (1998) Tissue Engineered Bone Repair of Calvarial Defects Using Cultured Periosteal Cells. Plast Reconstr Surg 101(3): 567-574.

44. Bakker AD, Schrooten J, van Cleynenbreugel T, Vanlauwe J, Lutyen J, et al. (2008) Quantitative Screening of Engineered Implants in a Long Bone Defect Model in Rabbits. Tissue Eng Part C Methods 14(3): 251-260.

45. Sakata Y, Ueno T, Kagawa T, Kanou M, Fuji T, et al. (2006) Osteogenic potential of cultured human periosteum-derived cells - A pilot study of human cell transplantation into a rat calvarial defect model. J CranioMaxillofacial Surg 34(8): 461-465.

46. Vacanti CA, Bonassar LJ, Vacanti MP, Shufflebarger J (2001) Replacement of an Avulsed Phalanx with Tissue-Engineered Bone. N Engl J Med 344(20): 1511-1514.

47. Erol 00, Sira M (1980) New capillary bed formation with a surgically constructed arteriovenous fistula. Plast Reconstr Surg 66(1): 109-115.

48. Hofer SOP, Knight KM, Cooper-White JJ, O Connor AJ, Perera JM, et al. (2003) Increasing the Volume of Vascularized Tissue Formation in Engineered Constructs: An Experimental Study in Rats. Plast Reconstr Surg 111(3): 1186-1192. 
49. Kneser U, Polykandriotis E, Ohnolz J, Heidner K, Grabinger L, et al. (2006) Engineering of Vascularized Transplantable Bone Tissues: Induction of Axial Vascularization in an Osteoconductive Matrix Using an Arteriovenous Loop. Tissue Eng 12(7): 1721-1731.

50. Arkudas A, Beier JP, Heidner K (2007) Axial Prevascularization of Porous Matrices Using an Arteriovenous Loop Promotes Survival and Differentiation of Transplanted Autologous Osteoblasts. Tissue Eng 13(7): 1549-1560.

ISSN: 2574-1241

DOI: 10.26717/BJSTR.2020.24.004082

Massimo Rigoni. Biomed J Sci \& Tech Res

(C) (P) This work is licensed under Creative

Submission Link: https://biomedres.us/submit-manuscript.php
51. Polykandriotis E, Arkudas A, Euler S, Beier J, Horch R, et al. (2006) Prävaskularisationsstrategien im Tissue Engineering. Handchirurgie. Mikrochirurgie. Plast Chir 38(4): 217-223.

52. Horch RE, Beier JP, Kneser U, Arkudas A (2014) Successful human longterm application of in situ bone tissue engineering. J Cell Mol Med 18(7): 1478-1485.

$\begin{array}{ll}\text { BIOMEDICAL } & \text { Assets of Publishing with us } \\ \text { RESEARCHES } & \text { - Global archiving of articles } \\ & \text { - Immediate, unrestricted online access } \\ \end{array}$

